\title{
DESEMPENHO DE GENÓTIPOS DE TRIGO INTRODUZIDOS DO MÉXICO NO ESTADO DE SÃO PAULO $\left(^{1}\right)$
}

\author{
GUSTAVO BARNABÉ BIUDES $\left({ }^{2,4}\right)$; CARLOS EDUARDO DE OLIVEIRA CAMARGO $\left({ }^{2,5^{*}}\right)$; \\ ANTONIO WILSON PENTEADO FERREIRA FILHO $\left({ }^{2}\right)$; JOAQUIM ADELINO \\ AZEVEDO FILHO $\left({ }^{3}\right)$
}

\begin{abstract}
RESUMO
Os trigos mexicanos apresentam características agronômicas de interesse podendo ser recomendados para cultivo em condições de solo onde o alumínio não é um fator limitante ou serem utilizados como fontes genéticas em programas de melhoramento. O objetivo deste estudo foi avaliar o comportamento agronômico de 18 linhagens de trigo introduzidos do Centro Internacional de Melhoramento do Milho e Trigo, Cimmyt, México e duas cultivares-controle IAC-24 e IAC-289, em um experimento instalado em Monte Alegre do Sul (SP), em condições de solo corrigido e irrigado por aspersão, no período de 19992002. Avaliaram-se os seguintes caracteres: produção de grãos, altura de plantas, acamamento, ciclo da emergência ao florescimento, comprimento da espiga, número de espiguetas por espiga, número de grãos por espiga e por espigueta e massa de cem grãos. L1 (SERI M 82) e L15 (DESCONHECIDO) destacaram-se para produção de grãos. L1 destacou-se pelo ciclo tardio, alto número de espiguetas por espiga e de grãos por espiga e baixa massa de cem grãos e L15, pela precocidade para florescer e elevada massa de cem grãos. L3 (FASAN) e L16 (KAUZ*2/ / TC*6/RL5406(RL6043)/3/KAUZ) destacaram-se pelo porte baixo; L6 (PRINIA) e L8 (CHIL/BUC), pelas espigas compridas; L3, pelo alto número de espiguetas por espiga; L9 (MUNIA/KAUZ) pelo grande número de grãos por espiga e por espigueta, e L18 (CETTIA), pelos grãos mais pesados. Em pelo menos dois anos, houve tendência de se obter maior produção de grãos em plantas semi-anãs mais altas com ciclo mais curto. Plantas produtivas apresentaram grãos pesados, espigas compridas com maior número de espiguetas e de grãos.
\end{abstract}

Palavras-chave: Triticum aestivum L., produção de grãos, altura de planta e caracteres agronômicos.

\section{ABSTRACT \\ BEHAVIOUR OF MEXICAN WHEAT GENOTYPES IN THE STATE OF SÃO PAULO}

The Mexican wheats present agronomic characteristics of interest being recommended for cultivation in soil conditions where aluminum is not a limiting factor or being utilized as genetic sources in breeding programs. The objective of this investigation was to evaluate 18 wheat inbred lines introduced from International Improvement Maize and Wheat Center, Cimmyt, Mexico, and the check cultivars IAC-24 and IAC-289 in trials carried out at Monte Alegre do Sul, SP, Brazil, in limed soil under sprinkler irrigation conditions, during 1999-2002. Grain yield, number of days from emergence to flowering, plant height, lodging, spike length, number of spikelets per spike, number of grains per spike and per spikelet as well as weight of 100 grains were estimated. L1 (SERI M 82) e L15 (UNKNOWN) presented high grain

( $\left.{ }^{1}\right)$ Recebido para publicação em 28 de setembro de 2006 e aceito em 3 de abril de 2007.

$\left({ }^{2}\right)$ Instituto Agronômico (IAC), Centro de Análise e Pesquisa Tecnológica do Agronegócio de Grãos e Fibras, Caixa Postal 28, 13020-432 Campinas (SP). E-mail: ccamargo@iac.sp.gov.br. $\left(^{*}\right)$ Autor correspondente

$\left({ }^{3}\right)$ Pólo Regional do Desenvolvimento Tecnológico dos Agronegócios do Leste Paulista, Caixa Postal 01, 13910-000 Monte Alegre do Sul (SP).

$\left({ }^{4}\right)$ Bolsista da Fundação de Apoio à Pesquisa Agrícola (FUNDAG).

$\left({ }^{5}\right)$ Com bolsa de produtividade em pesquisa do CNPq. 
yield. L1 was late and showed high spikelet and grain number per spike and low 100 grain weight and L15 was early to flower and exhibited high 100 grain weight. L3 (FASAN) and L16 (KAUZ*2//TC*6/ RL5406(RL6043)/3/KAUZ) had low semidwarf plants; L6 (PRINIA) and L8 (CHIL/BUC) showed long spikes; L3, the largest number spikelet per spike; L9 (MUNIA/KAUZ), the largest number of grain per spike and per spikelet, and L18 (CETTIA), the heaviest grains. During two years, higher grain yield were obtained in higher semidwarf plants of shorter cycle. Higher grain yield plants presented heavier grains, longer heads with higher number of spikelets and grains.

Key words: Triticum aestivum L., grain yield, plant height, agronomic characteristics.

\section{INTRODUÇÃO}

A intensificação das pesquisas no melhoramento genético de trigo no Estado de São Paulo, associado à adoção de técnicas culturais modernas, entre as quais o emprego da irrigação por aspersão, permitiu que a produtividade média de grãos que em 1972 era de $992 \mathrm{~kg} \mathrm{ha}^{-1} \mathrm{em} 25.000$ ha de área cultivada, alcançasse $2.350 \mathrm{~kg} \mathrm{ha}^{-1} \mathrm{em} 2005$, com área cultivada de 53.500 ha, representando aumento de aproximadamente $230 \%$ na produtividade e $210 \%$ na área plantada, em cerca de 30 anos de cultivo (CAMARGO, 1993; CONAB, 2006).

Grande parte dos avanços na cultura do trigo no Estado de São Paulo deve-se à obtenção, pelo programa de melhoramento genético do trigo do Instituto Agronômico (IAC), em Campinas, de cultivares superiores com alta produtividade, resistentes às principais doenças, tolerantes ao alumínio, de ciclo precoce e porte semi-anão. $\mathrm{O}$ uso dessas cultivares e o incremento na produtividade, permitiram a expansão da cultura do trigo para sistemas edafoclimáticos desfavoráveis no Estado (CAMARGO, 1993).

O programa de melhoramento do IAC vem introduzindo, anualmente, desde 1963, variedades e populações híbridas oriundas do Centro Internacional de Melhoramento de Milho e Trigo (CIMMYT) situado no México (CAmargo et al., 1988).

Os trigos mexicanos, embora sejam sensíveis à toxicidade do alumínio presente no solo, podem ter caracteres agronômicos de grande interesse, como: alto potencial produtivo aliado ao porte baixo (semi-anão), palha forte, resistência ao acamamento e à ferrugemda-folha, maior número de espiguetas férteis, maior perfilhamento, precocidade, respostas à adubação e ampla adaptação (CAMARGO, 1993; CAMARGO et al., 1996). Dessa forma, desde a década de 70 o programa de melhoramento do IAC tem procurado selecionar e recomendar linhagens mexicanas para cultivo em condições de solo corrigido e irrigado do Estado de São Paulo, destacando-se a recomendação das cultivares Anahuac, IAC-350 e IAC-370. Esse material também pode ser utilizado em cruzamentos com genótipos nacionais adaptados às condições de solo ácido, visando obter genótipos recombinantes com alto potencial produtivo, porte semi-anão e tolerantes à toxicidade de $\mathrm{Al}^{3+}$ (CAMARGO, 1993).

Embora a seleção para maior produção de grãos seja o principal objetivo da maioria dos programas de melhoramento genético, esse caráter é complexo e de herança poligênica, consequentemente de baixa herdabilidade e altamente influenciado pelos fatores do ambiente (Medeiros e Schleuber, 1971; Silva et al., 2005). Entretanto, a produção de grãos pode ser incrementada selecionando-se por meio de seus componentes, geralmente de controle genético menos complexo. Desta forma, é também muito importante investigar as inter-relações entre as caracteres avaliados e seus efeitos na produção de grãos (CAMARgo, 1999).

O presente trabalho tem por objetivos avaliar o comportamento agronômico de linhagens de trigo introduzidas do CIMMYT, quanto a produção de grãos e outros caracteres de importância agronômica, bem como estimar as correlações entre esses caracteres.

\section{MATERIAL E MÉTODOS}

Avaliou-se o comportamento agronômico de 20 genótipos de trigo sendo 18 linhagens introduzidas do México (CIMMYT) e duas cultivares nacionais IAC-24 e IAC-289, recomendadas para cultivo no Estado de São Paulo. A origem e a genealogia dos genótipos estão descritas na tabela 1.

Os experimentos foram instalados em 1999, 2000, 2001 e 2002, no Pólo Regional de Desenvolvimento Tecnológico dos Agronegócios do Leste Paulista, em Monte Alegre do Sul (SP), Brasil (latitude $22^{\circ} 41^{\prime} \mathrm{S}$, longitude $46^{\circ} 43^{\prime} \mathrm{W}$, altitude 777 $\mathrm{m})$, em Argissolo Vermelho-Amarelo, pertencente à zona tritícola $\mathrm{H}$, em condições de solo ácido corrigido com calcário e irrigado por aspersão.

O delineamento experimental utilizado foi o de blocos ao acaso, com quatro repetições e parcelas constituídas por seis linhas de $3 \mathrm{~m}$ de comprimento, espaçadas 0,2 $\mathrm{m}$ entre linhas e $0,6 \mathrm{~m}$ entre parcelas. A densidade de semeadura foi de 400 sementes viáveis por $\mathrm{m}^{2}$. 
Tabela 1. Origem e genealogia de 18 linhagens mexicanas e duas cultivares-controle de trigo avaliadas nos experimentos instalados no Pólo Regional de Desenvolvimento Tecnológico dos Agronegócios do Leste Paulista, em Monte Alegre do Sul (SP), de 1999 a 2002

\begin{tabular}{|c|c|c|}
\hline Cultivares e linhagens & Origem $\left({ }^{1}\right)$ & Genealogia \\
\hline IAC-24 & & IAS-51/4/SON64/Y50//GTO/2*CNO \\
\hline IAC-289 & & KVZ/BUHO"S" / / KAL/BB \\
\hline L1 & $5^{\text {th }}$ HTWYT T-2 & SERI M 82 \\
\hline L2 & $5^{\text {th }}$ HTWYT T-4 & MOCHIS T 88 \\
\hline L3 & $5^{\text {th }}$ HTWYT T-6 & FASAN \\
\hline L4 & $5^{\text {th }}$ HTWYT T-11 & TURACO \\
\hline L5 & $5^{\text {th }}$ HTWYT T-13 & ND/VG9144//KAL/BB/3/YACO/4/CHIL \\
\hline L6 & $5^{\text {th }}$ HTWYT T-15 & PRINIA \\
\hline L7 & $5^{\text {th }}$ HTWYT T-18 & TURACO/CHIL \\
\hline L8 & $5^{\text {th }}$ HTWYT T-22 & CHIL/BUC \\
\hline L9 & $5^{\text {th }}$ HTWYT T-28 & MUNIA/KAUZ \\
\hline L10 & $5^{\text {th }}$ HTWYT T-31 & HAHN/2*WEAVER \\
\hline L11 & $5^{\text {th }}$ HTWYT T-33 & HAHN/2*WEAVER \\
\hline L12 & $5^{\text {th }}$ HTWYT T-39 & KAUZ*2//DOVE/BUC/3/KAUZ \\
\hline L13 & $5^{\text {th }}$ HTWYT T-43 & $\mathrm{KAUZ}^{*} 2 / \mathrm{MNV} / / \mathrm{KAUZ}$ \\
\hline L14 & $5^{\text {th }}$ HTWYT T-46 & KAUZ*2//SAP/MON/3/KAUZ \\
\hline L15 & $5^{\text {th }}$ HTWYT T-50 & DESCONHECIDO \\
\hline L16 & $5^{\text {th }}$ HTWYT T-47 & KAUZ*2//TC*6/RL5406(RL6043)/3/KAUZ \\
\hline L17 & $5^{\text {th }}$ HTWYT T-10 & ALDAN/IAS 58//OPATA \\
\hline L18 & $5^{\text {th }}$ HTWYT T-16 & CETTIA \\
\hline
\end{tabular}

$\left.{ }^{1}\right)$ HTWYT - Heat Tolerant Wheat Yield Trial (Ensaio de linhagens de trigo tolerantes ao calor) originário do CIMMYT, México.

Retiraram-se amostras compostas de solos dos experimentos estudados nas profundidades de 0-20 $\mathrm{cm}$. Em vista das análises de solo e de acordo com as tabelas de adubação do IAC para o trigo (INSTITUTO Agronômico, 2002), na semeadura foi feita adubação com 4-14-8 (N, $\mathrm{P}_{2} \mathrm{O}_{5}$ e $\left.\mathrm{K}_{2} \mathrm{O}\right)$ e aos 30-40 dias após a emergência foi feita uma adubação de cobertura com sulfato de amônio (40 $\mathrm{kg} \mathrm{ha}^{-1}$ de $\left.\mathrm{N}\right)$.

Iniciou-se a irrigação por aspersão dos experimentos, logo após a semeadura, em intervalos de sete a dez dias (quando não ocorreram chuvas) e o término sucedeu próximo à maturação das plantas.

Avaliaram-se, em cada parcela, em todos os anos de cultivo, os seguintes caracteres agronômicos:

Produção de grãos: considerando a produção total de grãos, em gramas, obtida nas seis linhas de cada parcela, transformada em $\mathrm{kg} \mathrm{ha}^{-1}$.

Altura de plantas: compreende a distância em centímetros, do nível do solo ao ápice da espiga, excluindo-se as aristas, no início da maturação fisiológica, levando-se em consideração a média de diferentes pontos em cada parcela.
Ciclo da emergência ao florescimento: contando-se o número de dias decorridos entre a emergência das plântulas e o florescimento (quando mais de $50 \%$ das espigas floresceram).

Acamamento: avaliado considerando a porcentagem de plantas acamadas na época da maturação, empregando-se uma escala de zero (sem acamamento) até $100 \%$ (plantas totalmente acamadas), em apenas duas repetições.

Comprimento da espiga: considerando o comprimento médio, em centímetros, de cinco espigas tomadas ao acaso, excluindo-se as aristas, em cada parcela quando atingiram a maturação fisiológica.

Número de espiguetas por espiga: computando o número médio de espiguetas de cinco espigas tomadas ao acaso, em cada parcela, na maturação fisiológica.

Número de grãos por espiga: considerando o número médio de grãos contados em cinco espigas colhidas ao acaso, em cada parcela, na maturação fisiológica. 
Número de grãos por espigueta: obtido efetuando a divisão do número total de grãos pelo número total de espiguetas de cinco espigas coletadas de forma aleatória em cada parcela.

Massa de cem grãos: levando em consideração a massa, em gramas, de cem grãos de cinco espigas, tomados ao acaso, em cada parcela.

Para cada caráter avaliado, com exceção do acamamento, efetuou-se uma análise de variância individual, visando detectar efeitos de genótipos e repetições, e uma análise conjunta considerando todos os anos de cultivo, para detectar os efeitos de genótipos, anos e interação genótipos $\mathrm{x}$ anos. Nas análises conjuntas, utilizaram-se como estimativas do desvio padrão residual para genótipos e anos o quadrado médio da interação genótipos $x$ anos $\mathrm{e}$ para a interação genótipos $x$ anos o quadrado médio do erro.

Empregou-se o teste de Tukey, ao nível de 5\%, para comparar as médias dos genótipos para cada um dos caracteres avaliados.

Visando estimar o grau de associação entre os caracteres avaliados nos genótipos de trigo, foram calculadas correlações simples entre produção de grãos (PG), altura de plantas (AP), ciclo da emergência ao florescimento (CEF), comprimento da espiga (CE), número de espiguetas por espiga (NEGE), número de grãos por espiga (NGE), número de grãos por espigueta (NGEG) e massa de cem grãos (MCG). Consideraram-se os dados das 80 parcelas, em cada ano de cultivo e empregou-se o teste $t$, ao nível de 5\%, para avaliação da significância do coeficiente de correlação.

\section{RESULTADOS E DISCUSSÃO}

$\mathrm{Na}$ análise de variância conjunta para produção de grãos dos genótipos avaliados nos experimentos instalados em 1999, 2000, 2001 e 2002, os quadrados médios revelaram efeitos significativos $(\mathrm{P}<0,05)$ para genótipos e anos e não significativos para a interação genótipos $x$ anos. Na maioria dos genótipos avaliados não houve diferenças no padrão de resposta perante às variações de anos (Tabela 2). Esses resultados concordaram com os obtidos por Lовато et al. (2005), avaliando linhagens introduzidas do CIMMYT e com SALOMON et al. (2003), avaliando linhagens diaplóides de trigo em condições de solo corrigido e de irrigação por aspersão, respectivamente, em Ribeirão Preto e Monte Alegre do Sul.

Devido à ausência de interação genótipos $x$ anos para produção de grãos, os genótipos foram avaliados considerando a média nos quatro anos de cultivo (Tabela 2). Nessas condições L1 (3.096 kg ha ${ }^{-1}$ ) e L15 (3.075 kg ha-1) destacaram-se para produção de grãos, diferindo apenas da cultivar-controle IAC-24 $\left(2.109 \mathrm{~kg} \mathrm{ha}^{-1}\right)$ e de L2 $\left(2.475 \mathrm{~kg} \mathrm{ha}^{-1}\right), \mathrm{L} 5(2.438 \mathrm{~kg}$ $\left.\mathrm{ha}^{-1}\right)$, L13 $\left(2.477 \mathrm{~kg} \mathrm{ha}^{-1}\right)$ e L14 $\left(2.449 \mathrm{~kg} \mathrm{ha}^{-1}\right)$. A L1 também diferiu da L4 (2.517 $\left.\mathrm{kg} \mathrm{ha}^{-1}\right)$ e da L17 (2.513 $\left.\mathrm{kg} \mathrm{ha}^{-1}\right)$.

Avaliando a adaptabilidade e estabilidade desses mesmos genótipos em diferentes locais do Estado de São Paulo, incluindo Monte Alegre do Sul, Amorim et al. (2006), considerando apenas os anos de 2000 e 2001, verificou que as linhagens L1 e L11 bem como a cultivar IAC-289 destacaram-se das demais pela alta estabilidade de produção de grãos e ampla adaptabilidade aos diferentes locais considerados, constituindo-se em genótipos de interesse ao programa de melhoramento genético. A L15 também se sobressaiu quanto à produção de grãos, em Monte Alegre do Sul, mas não houve ampla adaptabilidade e alta estabilidade em diferentes locais, conforme AMOrim et al. (2006)

A análise de variância conjunta para altura de plantas revelou efeitos significativos $(\mathrm{P}<0,05)$ para genótipos e anos, e não significativo para a interação genótipos $x$ anos (Tabela 2). Em todos os genótipos avaliados, observaram-se plantas consideradas de porte semi-anão $(77$ a $94 \mathrm{~cm})$ concordando com LовAто et al. (2005) avaliando linhagens mexicanas, em diferentes locais paulistas. Considerando a média dos quatro anos de cultivo, L2 $(79 \mathrm{~cm}), \mathrm{L} 3(78 \mathrm{~cm}), \mathrm{L} 9$ $(80 \mathrm{~cm})$ e L16 $(77 \mathrm{~cm})$ destacaram-se com plantas de porte reduzido. Por outro lado, L5 $(93 \mathrm{~cm})$, L15 (93 $\mathrm{cm})$, L17 $(94 \mathrm{~cm})$ e L18 $(91 \mathrm{~cm})$ sobressaíram-se por exibir plantas de porte mais alto.

Avaliando o comportamento dos genótipos quanto ao acamamento, considerando a média dos quatro anos, a cultivar-controle IAC-289 (4\%) e L1 $(6 \%)$, L10 (5\%) e L11 (4\%), destacaram-se por mostrar as menores porcentagens de plantas acamadas associadas as plantas com altura intermediária (Tabela 2). Por outro lado L15 (19\%) e L17 $(25 \%)$ apresentaram elevado acamamento e tiveram plantas de porte mais alto, revelando uma tendência dos genótipos mais altos serem mais sensíveis ao acamamento. Entretanto, L13 (25\%) e L14 $(21 \%)$, que também apresentaram elevado acamamento, exibiram altura de plantas intermediárias, mostrando que o acamamento, embora seja influenciado pela altura de plantas, pode sofrer o efeito de outros fatores, como por exemplo, a consistência da palha e condições do ambiente como vento e chuva (SousA, 1998). 


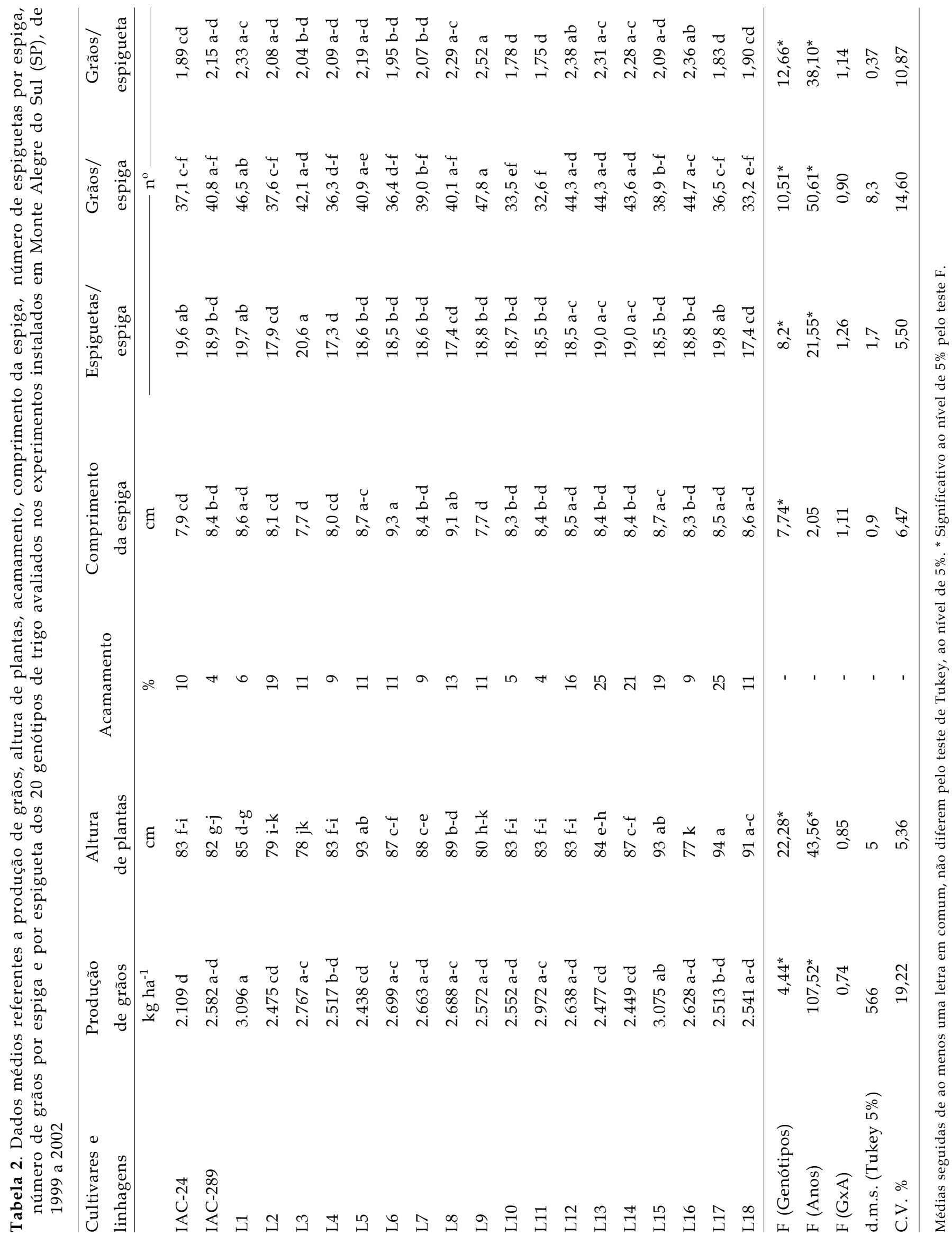


Avaliando linhagens de trigo provenientes de cruzamentos entre genótipos introduzidos do CIMMYT e nacionais, CAMARGO et al. (2001) também observaram uma tendência dos genótipos mais altos apresentarem uma porcentagem maior de acamamento, assim como Sousa (1998) avaliando cultivares de trigo no Rio Grande do Sul. Em ambientes onde há o emprego de irrigação e são utilizadas elevadas doses de adubação nitrogenada é recomendado o uso de genótipos com maior resistência ao acamamento por determinar redução de perda na produção e qualidade de grãos (Instituto Agronômico, 2002).

Os quadrados médios das análises conjuntas da variância para comprimento da espiga, número de espiguetas por espiga, número de grãos por espiga e por espigueta e massa de cem grãos, mostraram efeitos significativos de genótipos para todos os caracteres considerados; efeitos de anos significativos para número de espiguetas por espiga, número de grãos por espiga e por espigueta, e efeito da interação genótipos $x$ anos significativo apenas para massa de cem grãos (Tabelas 2 e 3).

Para comprimento da espiga, L6 $(9,3 \mathrm{~cm})$ destacou-se, considerando a média dos quatro anos de cultivo, não diferindo somente da L1 $(8,6 \mathrm{~cm})$, L5 $(8,7 \mathrm{~cm}), \mathrm{L} 8(9,1 \mathrm{~cm}), \mathrm{L} 12(8,5 \mathrm{~cm}), \mathrm{L} 15(8,7 \mathrm{~cm})$, L17 $(8,5 \mathrm{~cm})$ e L18 $(8,6 \mathrm{~cm})$ (Tabela 2$)$. Para número de espiguetas por espiga, a L3 $(20,6)$ se sobressaiu, não diferindo apenas da cultivar-controle IAC-24 $(19,6)$ e da L1 $(19,7), \operatorname{L12}(18,5), \operatorname{L13}(19,0), \operatorname{L} 14(19,0)$ e L17 $(19,8)$. L9 destacou-se quanto à fertilidade da espiga (número de grãos por espiga) e número de grãos por espigueta, não diferindo somente da cultivar-controle IAC-289 $(40,8)$ e da L1 $(46,5)$, L3 $(42,1)$, L5 $(40,9)$, L8 $(40,1)$, L12 $(44,3)$, L13 $(44,3)$, L14 $(43,6)$ e L16 $(44,7)$ para número de grãos por espiga e da cultivar-controle IAC-289 $(2,15)$ e da L1 $(2,33)$, L2 $(2,08)$, L4 (2,09), L5 (2,19), L8 $(2,29)$, L12 $(2,38)$, L13 $(2,31), \operatorname{L14}(2,28), \operatorname{L15}(2,09)$ e L16 $(2,36)$ para número de grãos por espigueta.

Embora para massa de cem grãos a interação genótipos $x$ anos tenha sido significativa, L15 e L18 sobressaíram-se para esse caráter em todos os anos de cultivo, mantendo seu comportamento mesmo em função das variações dos anos e não diferindo somente da L5 (3,90 g), L7 (4,23 g) e L8 (3,93 g) em 2000; da L5 (3,76 g) e L11 $(3,97 \mathrm{~g})$ em 2001 e da L8 $(4,21 \mathrm{~g})$ e L11 $(4,20$ g) em 2002 (Tabela 3). Pela grande estabilidade para massa de cem grãos, L15 e L18 constituem germoplasma de interesse para aumentar esse caráter em programas de melhoramento de trigo.
Fontes genéticas para comprimento da espiga, número de espiguetas por espiga, número de grãos por espiga, número de grãos por espigueta e massa de cem grãos também foram obtidos por CAmargo et al. (2001) e Lobato et al. (2005) avaliando genótipos de trigo em solos corrigidos e com irrigação por aspersão. Esses resultados evidenciam a presença de variabilidade genética para tais características ressaltando o potencial genético das linhagens introduzidas do México.

$\mathrm{Na}$ análise de variância individual para a característica ciclo da emergência ao florescimento, observaram-se efeitos de genótipos significativos $(\mathrm{P}<0,05)$, em todos os anos de cultivo (Tabela 3$)$. Quando considerados os quatro anos em conjunto, na análise de variância revelaram-se efeitos significativos para genótipos, anos e interação genótipos $x$ anos. Entretanto, apesar desses resultados indicarem diferença no padrão de resposta dos genótipos decorrentes do ano de avaliação, nos quatro anos de cultivo, L4 e L15 distinguiram-se quanto ao ciclo precoce e L1, L12, L13 e L14 destacaram-se pelo florescimento tardio. A utilização de genótipos precoces pode ser uma alternativa de cultivo visando ao melhor aproveitamento do solo na sucessão de culturas (CAmargo, 1993).

Os coeficientes de variação (CV) obtidos para produção de grãos e também para as demais características foram sempre abaixo de $20 \%$, demonstrando haver pouca influência do erro experimental e, consequentemente, boa precisão nos resultados (Tabelas 2 e 3 ).

As correlações simples entre as características agronômicas avaliadas, com exceção de acamamento, são apresentadas na tabela 4. Para a maioria das correlações obtidas entre as características avaliadas, houve uma tendência dos valores estimados serem de mesma magnitude e sinal ao longo dos anos de cultivo, indicando consistência nas correlações obtidas mesmo considerando diferentes anos.

Correlações significativas e positivas entre produção de grãos e altura de plantas, comprimento da espiga, número de espiguetas por espiga e número de grãos por espiga foram detectadas quando se consideraram os ensaios de 1999 e 2002. Esses resultados revelaram uma tendência dos genótipos mais produtivos terem plantas de porte semi-anão mais altas, o que também foi verificado por SALOMON et al. (2003). Plantas mais produtivas associaram-se também com aquelas de espigas mais compridas e mais férteis e maior número de espiguetas. 


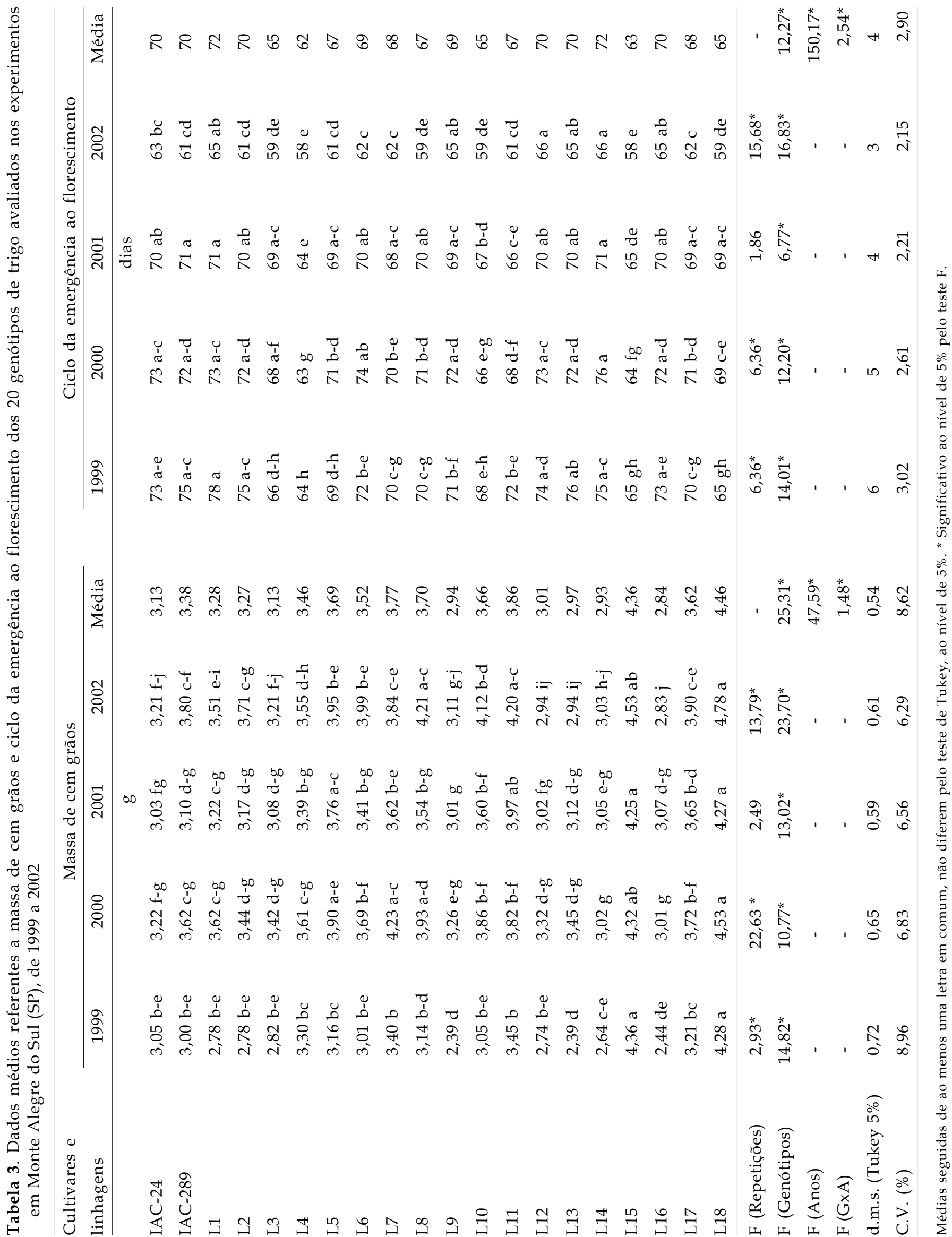


Houve ainda uma tendência de genótipos mais produtivos terem os grãos mais pesados e ciclo vegetativo (emergência ao florescimento) mais precoce, em 1999 e 2000 (Tabela 4). Correlações significativas e positivas entre produção de grãos e massa de cem grãos também foram observadas por MoRAL et al. (2003), avaliando linhagens de trigo duro introduzidas do CIMMYT, em condições de irrigação, em Gimenells (Espanha) e por Silva et al. (2005), avaliando genótipos de trigo comum, em Pelotas (Brasil). Em trabalhos publicados em São Paulo, foi observado que os genótipos de trigo mais precoces para florescer, com ciclo vegetativo curto, são também os mais precoces para maturar, ou seja, de ciclo reprodutivo curto (LobATO, 2006). O mesmo autor obteve associações negativas entre a produção de grãos de trigo e o ciclo vegetativo em condição de irrigação por aspersão.

Correlações elevadas e positivas entre produção de grãos com número de grãos por espiga e massa de grãos em populações híbridas de trigo, obtidas por CAMARGO (1999), em condições controladas no telado, concordaram parcialmente com resultados deste trabalho.

As correlações apresentadas na tabela 4 revelaram, de uma maneira geral, que os genótipos com grãos mais pesados foram mais produtivos, com plantas mais altas, espigas mais compridas e ciclo precoce aliados aos menores números de espiguetas por espiga e à menor fertilidade da espiga.

Tabela 4. Correlações simples entre produção de grãos e outras características agronômicas observadas nos genótipos, avaliados em cada experimento instalado de 1999, 2000, 2001 e 2002 em Monte Alegre do Sul (SP)

\begin{tabular}{|c|c|c|c|c|c|c|c|c|}
\hline Características & Anos & PG & $\mathrm{AP}$ & CEF & $\mathrm{CE}$ & NEGE & NGE & NGEG \\
\hline \multirow[t]{4}{*}{$\mathrm{AP}$} & 1999 & $0,38^{*}$ & - & - & - & - & - & - \\
\hline & 2000 & 0,18 & - & - & - & - & - & - \\
\hline & 2001 & $-0,01$ & - & - & - & - & - & - \\
\hline & 2002 & $0,48^{*}$ & - & - & - & - & - & - \\
\hline \multirow[t]{4}{*}{ CEF } & 1999 & $-0,22^{*}$ & $-0,34^{*}$ & - & - & - & - & - \\
\hline & 2000 & $-0,24^{*}$ & $-0,01$ & - & - & - & - & - \\
\hline & 2001 & $-0,08$ & 0,03 & - & - & - & - & - \\
\hline & 2002 & 0,12 & $-0,03$ & - & - & - & - & - \\
\hline \multirow[t]{4}{*}{$\mathrm{CE}$} & 1999 & $0,49 *$ & $0,61^{*}$ & 0,08 & - & - & - & - \\
\hline & 2000 & 0,08 & $0,42^{*}$ & 0,21 & - & - & - & - \\
\hline & 2001 & 0,19 & $0,31^{*}$ & 0,18 & - & - & - & - \\
\hline & 2002 & $0,65^{*}$ & $0,56^{*}$ & 0,05 & - & - & - & - \\
\hline \multirow[t]{4}{*}{ NEGE } & 1999 & $0,40^{*}$ & $0,31^{*}$ & 0,12 & $0,53^{*}$ & - & - & - \\
\hline & 2000 & 0,11 & 0,12 & $0,23^{*}$ & $0,22^{*}$ & - & - & - \\
\hline & 2001 & 0,01 & $-0,02$ & $0,24^{*}$ & 0,10 & - & - & - \\
\hline & 2002 & $0,28^{*}$ & 0,14 & $0,43^{*}$ & $0,33^{*}$ & - & - & - \\
\hline \multirow[t]{4}{*}{ NGE } & 1999 & $0,32^{*}$ & 0,02 & $0,34^{*}$ & $0,47^{*}$ & $0,62^{*}$ & - & - \\
\hline & 2000 & 0,03 & 0,02 & $0,37^{*}$ & $0,37^{*}$ & $0,39 *$ & - & - \\
\hline & 2001 & 0,14 & $-0,13$ & $0,35^{*}$ & 0,30 * & $0,37^{*}$ & - & - \\
\hline & 2002 & $0,28^{*}$ & $-0,05$ & $0,39 *$ & $0,37^{*}$ & $0,39 *$ & - & - \\
\hline \multirow[t]{4}{*}{ NGEG } & 1999 & 0,17 & $-0,13$ & $0,35^{*}$ & 0,32 * & $0,25^{*}$ & $0,91^{*}$ & - \\
\hline & 2000 & 0,01 & $-0,01$ & $0,32 *$ & $0,32^{*}$ & 0,07 & $0,95^{*}$ & - \\
\hline & 2001 & 0,13 & $-0,13$ & $0,26^{*}$ & $0,27^{*}$ & $-0,05$ & $0,91^{*}$ & - \\
\hline & 2002 & 0,16 & $-0,13$ & 0,20 & $0,25^{*}$ & $-0,06$ & $0,89^{*}$ & - \\
\hline \multirow[t]{4}{*}{ MCG } & 1999 & $0,34^{*}$ & $0,53^{*}$ & $-0,60^{*}$ & $0,23^{*}$ & $-0,18$ & $-0,40^{*}$ & $-0,41^{*}$ \\
\hline & 2000 & $0,22^{*}$ & 0,20 & $-0,50^{*}$ & $0,24^{*}$ & $-0,31^{*}$ & $-0,43^{*}$ & $-0,36^{*}$ \\
\hline & 2001 & 0,13 & $0,51^{*}$ & $-0,39^{*}$ & $0,33^{*}$ & $-0,35^{*}$ & $-0,39^{*}$ & $-0,27^{*}$ \\
\hline & 2002 & 0,03 & $0,33^{*}$ & $-0,74^{*}$ & 0,20 & $-0,46^{*}$ & $-0,51^{*}$ & $-0,33^{*}$ \\
\hline
\end{tabular}

PG: produção de grãos $\left(\mathrm{kg} \mathrm{ha}^{-1}\right)$; AP: altura de plantas $(\mathrm{cm})$; CEF: ciclo da emergência ao florescimento (dias); CE: comprimento da espiga $(\mathrm{cm})$; NEGE: número de espiguetas por espiga; NGE: número de grãos por espiga; NGEG: número de grãos por espigueta e MCG: massa de cem grãos (g). * significativo, ao nível de $5 \%$, pelo teste $t$. 
Os genótipos mais tardios obtiveram a maior fertilidade, maior número de espiguetas por espiga, porém com grãos mais leves.

As espigas mais compridas foram obtidas nas plantas mais altas e obtiveram maior fertilidade e maior número de espiguetas por espigas.

\section{CONCLUSÕES}

1. L1 e L15 destacaram-se quanto à produção de grãos; em L1, além do ciclo tardio, foram observados alto número de espiguetas por espiga e de grãos por espiga e baixa massa de cem grãos; L15 destacou-se pela precocidade para florescer e elevada massa de cem grãos.

2. L3 e L16 sobressaíram-se pelo porte semianão mais baixo; L6 e L8 pelas espigas compridas; L3 pelo alto número de espiguetas por espiga; L9 pelo grande número de grãos por espiga e por espigueta; e a L18 pelos grãos mais pesados.

3. Em pelo menos dois anos, houve tendência da maior produção de grãos ser obtida em plantas semi-anãs mais altas com ciclo mais curto. Em plantas mais produtivas, observaram-se grãos mais pesados, espigas mais compridas, com maior número de espiguetas e de grãos.

\section{AGRADECIMENTOS}

Ao Centro Internacional de Melhoramento de Milho e Trigo (CIMMYT), pelo fornecimento dos genótipos e ao Conselho Nacional de Desenvolvimento Científico e Tecnológico (CNPq), pela concessão de bolsa.

\section{REFERÊNCIAS}

AMORIM, E.P.; CAMARGO, C.E.O.; FELICIO, J.C.; FERREIRA FILHO, A.W.P.; PETTINELLI JUNIOR, A.; GALLO, P.B.; AZEVEDO FILHO, J.A. Adaptabilidade e estabilidade de linhagens de trigo no Estado de São Paulo. Bragantia, Campinas, v.65, n.4, p.575-582, 2006.

CAMARGO, C.E.O. Componentes da produção e tolerância à toxicidade de alumínio em populações híbridas de trigo: estimativas de variâncias, herdabilidade e correlações. Ciência Agrotecnologia, Lavras, v.23, n.3, p.500-509, 1999.

CAMARGO, C.E. de O. Trigo. In: FURLANI, A.M.C.; VIEGAS, G.P. (Ed.). O melhoramento de plantas no Instituto Agronômico. Campinas: Instituto Agronômico, 1993. cap.12, p.433-488.
CAMARGO, C.E. deO.; FELICIO, J.C.;FERREIRA FILHO, A.W.P. Variedades de trigo para o Estado de São Paulo. Campinas, Instituto Agronômico, 1996. 20p. (Boletim Técnico, 163)

CAMARGO, C.E. de O.; FELICIO, J.C.; FERREIRA FILHO, A.W.P.; BARROS, B.C.; ALVES, J.C.V.N.; PETTINELLI JUNIOR, A. Comportamento agronômico de linhagens de trigo no Estado de São Paulo. Bragantia, Campinas, v.60, n.1, p.35-44, 2001.

CAMARGO, C.E. de O.; FELICIO, J.C.; FREITAS, J.G..; FERREIRA FILHO, A.W.P.; BARROS, B.C.; PETTINELLI JUNIOR, A.; SANTOS, R.R..; KANTHACK, R.A.D.; ROCHA JUNIOR, L. S. Melhoramento do trigo: comportamento de linhagens de origem mexicana no Estado de São Paulo. Bragantia, Campinas, v. 47, n.1, p.25-41, 1988.

CONAB. Indicadores de safras da Companhia Nacional de Abastecimento. Disponível em: http//www.conab.gov.br. Acesso em 15 de janeiro de 2006.

INSTITUTO AGRONÔMICO (CAMPINAS). Recomendações da Comissão Técnica de Trigo para 2002. 2.ed.atual. Campinas, 2002. 92p. (Boletim Técnico IAC, 196)

LOBATO, M.T.V. Desempenho Agronômico de genótipos de trigo em diferentes regiões do Estado de São Paulo. 2006. 160 f. Tese (Mestrado) - Instituto Agronômico, Campinas, 2006.

LOBATO, M.T.V.; CAMARGO, C.E. de O.; FERREIRA FILHO, A.W.P; BARROS, B.C.; PETTINELI JUNIOR, A.; PEREIRA, J.C.V.N.A.; GALLO, P.B. Desempenho de linhagens de trigo mexicanas, em condição de irrigação por aspersão no Estado de São Paulo. Arquivos do Instituto Biológico, São Paulo, v.72, n.2, p.211-219, 2005.

MEDEIROS, M.C.; SCLHEHUBER, A.M. Produção de grãos e componentes de produção de certas variedades brasileiras de trigo. Pesquisa Agropecuária Brasileira, Brasília, v. 6, p. 45-52, 1971.

MORAL, L. F. G. del; RHARRABTI, Y.; VILLEGAS, D.; ROYO, C. Evaluation grain yield and its components in durum wheat under Mediterranean conditions: an ontogenic approach. Agronomy Journal, Madison, v. 95, p. 266-274, 2003.

SALOMON, M. V.; CAMARGO, C. E. de O; PETTINELLI JUNIOR, A.; AZEVEDO FILHO, J. A. Performance of dihaploid wheat lines obtained via anther culture. Scientia Agricola, Piracicaba, v. 60, n.1, p.43-50, 2003.

SILVA, S.A., CARVALHO, F.I.F.; NEDEL, J.L.; CRUZ, P.J.;SILVA, J.A.G., CAETANO, V.R.; HARTWIG, I., SOUSA, C.S. Análise de trilha para os componentes de rendimentos de grãos em trigo. Bragantia, Campinas, v. 64, n. 2, p.191-196, 2005.

SOUSA, C.N.A. O acamamento e a reação de cultivares de trigo recomendadas no Rio Grande do Sul. Pesquisa Agropecuária Brasileira, Brasília, v. 33, n.5, p. 537-541, 1998 (número especial). 